\title{
A DRAMATIZAÇÃO NO ESPAÇO HOSPITALAR: UMA ESTRATÉGIA DE PESQUISA COM CRIANÇAS
}

\author{
The dramatization in the hospital space work: a strategy of \\ research with children. \\ El drama en el espacio hospitalario: una estrategia para la \\ investigación con niños
}

\author{
Sylvia Alves Cibreiros ${ }^{1}$
}

Isabel Cristina dos Santos Oliveira ${ }^{2}$

\section{RESUMO}

0 estudo tem por objetivo descrever a dramatização como uma abordagem metodológica, explicitando sua concepção teórica e a coleta de dados dessa estratégia nas pesquisas qualitativas com escolares hospitalizadas. A dramatização vincula-se ao brincar, uma forma de linguagem na infância, e mostrou-se como uma estratégia de coleta de dados promissora a ser usada por pesquisadores que desejem conhecer as percepções e entendimento das crianças sobre os diversos contextos de vida e papéis sociais, constituindo-se em opção de abordagem das crianças em pesquisas qualitativas.

Palavras-chave: Enfermagem Pediátrica. Criança Hospitalizada. Pesquisa Qualitativa. Coleta de Dados.

\begin{abstract}
The study has the objective of describing the dramatization as a methodological approach, in order to explicit the theoretical concept, and the data collection of that strategy in the qualitative researches with hospitalized school age children. The dramatization is bound to play, a form of language in childhood and was a strategy for data collection promising to be used by researchers wishing to know the perceptions and agreement from the children on the subject of the diverse arguments of life and social paper, being an option to work with children in the qualitative research.
\end{abstract}

Keywords: Pediatric Nursing. Child, Hospitalized. Qualitative Research. Data Collection.

\section{Resumen}

El objetivo del presente estudio es describir la representación dramática como un abordaje metodológico, destacando el marco teórico y la recopilación de datos de esta estrategia en la investigación cualitativa con alumnos hospitalizados. El drama se vincula a jugar, una forma de lenguaje en la infancia que demostró ser una estrategia eficaz para la recolección de datos que puede ser usada por los investigadores que buscan conocer la percepción y la comprensión de los niños - en diversos contextos de la vida y en diferentes roles sociales convirtiéndose en una opción válida para el abordaje en la investigación cualitativa con niños.

Palabras clave: Enfermería Pediátrica. Niño Hospitalizado. Investigación Cualitativa. Recolección de Datos

'Doutora em Enfermagem. Professora Assistente do Departamento de Enfermagem Materno-Infantil da Faculdade de Enfermagem da Universidade do

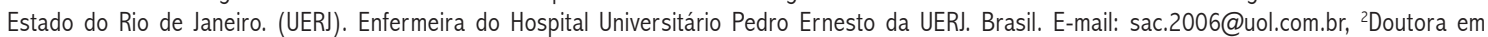
Enfermagem. Professora Associada do Departamento de Enfermagem Médico-Cirúrgica da Escola de Enfermagem Anna Nery da Universidade Federal do Rio de Janeiro. Pesquisadora/ CNPq. Brasil. E-mail: chabucris@ig.com.br 
A Dramatização no Espaço Hospitalar

Cibreiros Sa, Oliveira ICS

\section{INTRODUCÃO}

Uma das escolhas para o desenvolvimento de uma pesquisa é o tipo de abordagem. As pesquisas podem ser de natureza qualitativa ou quantitativa. Na realidade, é a situação, o problema que se deseja pesquisar, ou em outras palavras, 0 objeto de estudo, que aponta o tipo de pesquisa mais adequada para a investigação das questões que inquietam o pesquisador. ${ }^{1}$

Durante muito tempo, a abordagem quantitativa predominou no desenvolvimento dos estudos científicos, inclusive nas áreas social e humanas, que são carreadas de subjetividade. Muitos de seus objetos de estudo não eram adequadamente tratados e analisados com seu arsenal estatístico ou numérico. Como descrever em números, a vivência de uma pessoa? Como quantificar a emoção sentida por um ser humano?

Assim, a pesquisa qualitativa surgiu como alternativa de um método mais adequado aos contextos e problemáticas presentes nos estudos da antropologia e sociologia e, nos últimos 30 anos, vem se difundindo para as demais áreas, como psicologia, educação e administração. ${ }^{2}$

Os trabalhos presentes nos periódicos de enfermagem demonstram que a pesquisa qualitativa vem sendo cada vez mais utilizada nessa área. ${ }^{3}$ Este tipo de pesquisa tenta perceber, entender, compreender ou interpretar os fenômenos a partir da apreensão dos sujeitos em seu cenário natural. Valoriza as percepções e a subjetividade do indivíduo, considerando-o como um ser único e singular na defesa de que os conhecimentos sobre os indivíduos só são possíveis com a descrição da experiência humana, do modo como ela é vivida e como é definida por seus próprios sujeitos. ${ }^{4}$

Dessa forma, a pesquisa qualitativa aplicada à área da saúde lida com o mundo de significados, motivações, aspirações, crenças, valores e atitudes, que se traduz como um espaço mais intenso das relações, dos processos e dos fenômenos. ${ }^{5}$

Quanto às distinções existentes nas pesquisas qualitativa e quantitativa, cabe ressaltar que a pesquisa qualitativa está mais voltada à construção de novos conceitos do que a aplicações de conceitos já existentes; ao estudo de casos particulares em detrimento de grandes populações; à descrição dos significados das ações individuais mais do que codificar contextos; a lidar com a subjetividade, e não testar hipóteses; à análise dos dados com base nas interpretações, e não com bases estatísticas, dentre outras diferenças. ${ }^{6}$

0 pesquisador que, em virtude de sua posição epistemológica, opta pela abordagem qualitativa como recurso metodológico, precisa pensar sobre as estratégias de aquisição dos dados mais apropriadas aos objetivos do estudo. 0 pesquisador que opta pela abordagem qualitativa deve levar em conta a participação do sujeito como um dos elementos de seu fazer científico.

A pesquisa qualitativa utiliza diversos métodos e técnicas de produção de dados, como a pesquisa documental; a entrevista
Esc Anna Nery Rev Enferm 2010 jan-mar; 14 (1): 165-70

aberta e a semiestruturada, individual ou coletiva; a observação livre e do tipo participante, entre outros.

Ao escolher um método ou técnica para produzir dados para a pesquisa, o pesquisador não deve perder de vista algumas características dos sujeitos que podem interferir ou implicar esta produção, como o perfil pessoal e sociocultural, dentre outras que o pesquisador julgar pertinente.

No tocante à pesquisa desenvolvida com crianças, é importante que o pesquisador conheça algumas características relacionadas ao desenvolvimento infantil a fim de que sua opção por uma determinada proposta metodológica não venha a gerar frustrações ou seja ineficaz para produzir dados de análise de pesquisa.

A infância é uma época singular da trajetória do ser humano, em que os aspectos ligados ao crescimento e desenvolvimento estão presentes, como, por exemplo, o crescimento longitudinal, a maturação de órgãos e sistemas, a aquisição de habilidades físicas e o desenvolvimento da fala e da escrita.

Essas especificidades devem ser consideradas pelo pesquisador que irá abordar crianças como sujeitos em suas pesquisas, sobretudo no que tange ao desenvolvimento cognitivo. Essa área se relaciona às alterações intelectuais que se processam no decorrer da infância e conferem à criança variados modos de pensar de acordo com a fase do seu desenvolvimento.

Neste aspecto, é necessário que o pesquisador, ao escolher a faixa etária das crianças/sujeitos da sua pesquisa, conheça as peculiaridades do desenvolvimento cognitivo em que estas se encontram. Com isso, ele deve proceder à escolha de uma estratégia metodológica pertinente, que leve em conta estas especificidades como condição primordial para que se consiga abordar os sujeitos de forma adequada e inteligível a fim de que a coleta de dados venha a atender aos objetivos da pesquisa.

Assim sendo, o estudo tem por objetivo a dramatização como uma abordagem metodológica, explicitando sua concepção teórica e a coleta de dados dessa estratégia nas pesquisas qualitativas com escolares hospitalizados.

\section{A dramatização como estratégia de coleta de dados}

A dramatização ${ }^{a}$ foi a estratégia instituída para a coleta de dados e baseou-se na brincadeira de faz de conta, na qual a criança desenvolve atividades de simulação. A criança pode ser, estar e fazer o quiser, a partir do uso de sua imaginação. ${ }^{8}$

A brincadeira do faz-de-conta, com base no imaginário, possui regras a serem seguidas. Ao brincar de professora, por exemplo, a criança deverá agir como se fosse uma professora de verdade, exibindo seus comportamentos. A criança irá representar o papel que ela crê como sendo o de uma professora de verdade. São as regras da brincadeira de faz-de-conta, dentre as demais, que proporcionam um funcionamento mental mais avançado na criança. Ao exibir um comportamento semelhante ao papel desempenhado na brincadeira, a criança 
adquire o entendimento de cada um dos papéis presentes em seu meio sociocultural. ${ }^{9}$

A brincadeira de mãe se tornará longínqua quando a menina se tornar uma mãe real, todavia, na brincadeira se estabeleceram as linhas básicas e os fundamentos da futura experiência interior, que ajudará à criança a vivenciar no real aquilo que vivenciou por meio da brincadeira. ${ }^{9}$

A representação de papéis presentes nas brincadeiras de faz-de-conta permite compreender as concepções da criança acerca dos diversos papéis presentes na sociedade, já que ela irá representar baseada em suas percepções sobre os indivíduos no desempenho de determinados papéis.

Assim, ao buscar entender o cuidado de enfermagem pela perspectiva do escolar hospitalizado, e tendo como referencial teórico as concepções de Vygotsky, afirmando que, na brincadeira de faz-de-conta, a criança tem a capacidade de representação de papéis encontrados no cotidiano, utilizei a dramatização como estratégia de produção de dados da pesquisa.

0 cenário do estudo foi a unidade de internação de um hospital universitário pediátrico do município do Rio de Janeiro, pertencente à rede federal de ensino. Os sujeitos do estudo foram quatro escolares do sexo feminino, na faixa etária compreendida entre 6 e 12 anos. As escolares tiveram suas identidades resguardadas, e foram utilizados pseudônimos escolhidos pelas próprias escolares.

No estudo foram estabelecidos alguns critérios para a inclusão dos sujeitos/escolares, a saber: deveriam estar internados com diagnósticos médicos de patologias clínicas, sem delimitação de um tipo de patologia específica; não poderiam estar em fase terminal ou em estado grave, mas clinicamente estáveis; não deveriam apresentar dores ou desconfortos no momento da coleta de depoimentos; poderiam ter ou não internações anteriores; necessitariam apresentar um tempo de internação igual ou superior a 10 dias. Embora a escolha do número de dias de internação tenha sido arbitrária, pretendia-se com isso ter a garantia da experiência dos sujeitos em relação aos cuidados desenvolvidos na unidade de internação pediátrica a fim de que os mesmos pudessem ser representados durante a dramatização.

Assim sendo, desenvolvi os seguintes procedimentos para coleta dos dados: Ao encontrar uma escolar que contemplasse os critérios de inclusão como sujeito da pesquisa, eu primeiramente conversava com ela a respeito do estudo, das atividades previstas e seus objetivos. Diante da aceitação da escolar para participar do trabalho, eu fazia contato com seu responsável legal e informava que estava desenvolvendo uma pesquisa, explanava sobre os objetivos, as estratégias de coleta de depoimentos e a garantia do anonimato da escolar e solicitava a permissão por escrito por parte do responsável, para que a escolar pudesse participar do estudo. A assinatura do Termo de Consentimento Livre e Esclarecido (TCLE) por parte do responsável pela criança tem como objetivo atender às normas éticas referentes à Resolução n 196/96 do Ministério da Saúde. ${ }^{10}$

0 consentimento do responsável somente era fornecido após a concordância da escolar em participar do estudo, ou seja, a adesão à pesquisa dependia da vontade do escolar e da aquiescência do seu responsável.

Cabe salientar que também foi elaborado um Termo de Assentimento para que os sujeitos da pesquisa assinassem, com o intuito de registrar seu aceite em participar do estudo. Esse procedimento valoriza a vontade e a condição de cidadão da criança. Este documento também foi apreciado pelos responsáveis pelos sujeitos de pesquisa. Da mesma forma, foi feita a leitura prévia do documento para as escolares, antes da assinatura. Vale ressaltar que no Termo de Consentimento Livre e Esclarecido, e também no Termo de Assentimento, constava a solicitação de autorização para a utilização de gravador e filmagem durante a coleta de dados para a pesquisa.

Depois disso, eu preparava o cenário da dramatização. Esse era montado em uma ampla sala dentro da unidade de internação pediátrica. Nela, havia várias cadeiras; uma cama, que foi transformada na cama do paciente; uma mesa, onde foi simulado um posto de enfermagem, e eram colocados os objetos reais ou similares de brinquedo, de artefatos ligados ao universo de procedimentos técnicos hospitalares, ou seja, termômetros, estetoscópios, aparelhos de pressão arterial, seringas, esparadrapos, gazes, dentre outros objetos a serem manipulados pelas escolares durante a dramatização. Cabe enfatizar que foram excluídos os objetos de natureza perfurocortante, como scalps, jelcos, lâminas de bisturi, dentre outros, assim como medicamentos reais para o manuseio das escolares durante a dramatização a fim de se resguardar a integridade física delas.

Após a organização do cenário da dramatização, eu convidava as escolares para participarem da dramatização, em que uma delas representaria o papel de enfermeirab; outra, 0 papel de médica, e outras duas representariam os papéis da criança internada, a ser cuidada pela enfermeira, e de responsável pela criança que se encontrava internada. É necessário explicitar que estava prevista a representação de quatro papéis na dramatização: de médica, de enfermeira, de paciente e de seu responsável. Todavia, nas duas dramatizações feitas para a coleta de dados do estudo só havia três escolares aptas, tendo em vista os critérios de inclusão dos sujeitos, e dispostas a participar da pesquisa. Assim sendo, quando as escolares vieram para o cenário, foi procedida a escolha dos papéis. As próprias escolares tiveram a liberdade de selecionar os quatro papéis que desejariam representar, e, como nas duas dramatizações nenhuma das escolares optou por representar o papel de acompanhante, houve a necessidade de suprimir a figura do acompanhante nas dramatizações.

Após as escolha dos papéis, eu propunha que cada escolar fizesse de conta que era uma enfermeira, uma médica e uma criança internada e começassem a encenar a dramatização. Com base na experiência de internação hospitalar, na qual elas 
observaram e se relacionaram com essas pessoas, elas representariam seus papéis e passariam a atuar como se assim fossem, e espontaneamente vivenciariam esses papéis na dramatização.

A escolha pelo médico, em detrimento dos diversos profissionais que prestam assistência às crianças dentro das unidades de pediatria, baseou-se na historicidade dessa profissão associada ao ambiente hospitalar, na hegemonia médica, ${ }^{11}$ e também no senso comum, já que, ao se pensar em um profissional que atua em hospitais, é quase impossível não se lembrar da figura do médico. Quanto ao profissional enfermeiro, essa escolha veio de encontro à essência da temática do meu estudo, que buscava entender o cuidado prestado pela enfermagem, sob perspectiva do escolar hospitalizado, e que fundamentalmente teria que associá-lo ao enfermeiro.

A coleta de dados aconteceu nos dias 14 e 25 de julho de 2006 com um grupo de três escolares em cada dramatização; duas escolares participaram das duas dramatizações, totalizando, assim, quatro escolares como sujeitos da pesquisa. 0 tempo médio de cada dramatização foi de uma hora e meia.

Foi planejado, a priori, apenas um momento de dramatização para cada grupo de escolares, porém, se as escolares demonstrassem o desejo de trocar de papéis entre si, após o primeiro momento da dramatização, seria feita a troca de papéis com a encenação de um segundo momento de dramatização. Todavia, nas duas dramatizações, as escolares não demonstraram tal desejo, sendo realizado apenas um momento de dramatização, sem troca de papéis.

As dramatizações foram feitas em um horário determinado após a avaliação feita por mim e pela equipe multiprofissional que prestava assistência às escolares, para evitar interferência nos procedimentos terapêuticos aos quais as escolares deveriam ser submetidas. Os responsáveis pelas escolares foram convidados e tiveram liberdade de assistir a dramatização, porém nenhum deles exibiu esse desejo.

As duas dramatizações foram videogravadas, desde o seu início até o término, pois, deste modo, foi possível captar as ações das escolares relacionadas com as falas, que foram também gravadas na filmagem, permitindo sua observação, quantas vezes fossem necessárias, para obtenção dos dados a serem utilizados na análise. Também foi usado um gravador com fitas-cassetes para capturar as falas das escolares.

Decidi proceder à filmagem com a câmera em movimento, já que poderia me deslocar, focar a imagem nas ações mais relevantes, aproximando-a, e me movimentando; ou seja, poderia usufruir ao máximo o recurso da filmagem.

No segundo dia de dramatização, resolvi fazer um teste colocando a câmera para filmar, parada, sobre um tripé, por alguns minutos. Mas essa opção se mostrou inadequada, pois restringia, em muito, o campo de visão da dramatização, e, como as escolares se movimentavam, tornava-se impossível captar todas as suas ações.
Nesse contexto, cabe explicar que, embora a filmagem fosse um recurso que possibilitaria a captação de imagens e também a verbalização dos escolares, eu escolhi também fazer uso do gravador no intuito de não perder nenhuma fala que inadvertidamente a filmadora viesse a captar de forma distorcida ou mesmo em tom inaudível.

A videogravação contribui para melhorar a precisão ou coerência com que o observador apreende o fenômeno, uma vez que permite a exposição repetida do observador à mesma ocorrência do observado, assim como amplia a possibilidade de o observador repensar o observado, ou seja, amplifica sua capacidade de análise. ${ }^{12}$

Ao final da dramatização, as falas captadas por meio das fitas-cassetes com o gravador foram transcritas. Para a descrição exata das cenas, foi necessário assistir ao filme da dramatização e ouvir a fita-cassete concomitantemente. À medida que eu descrevia a cena observada na filmagem da dramatização, também escrevia as falas correspondentes das escolares presentes nas fitas-cassetes. Esse foi, certamente, um aspecto trabalhoso, porém necessário, já que muitas vezes a videogravação não era capaz de captar claramente as falas das escolares, ficando a gravação das falas como um aspecto imprescindível para a descrição fidedigna das cenas.

A análise foi feita com base na atuação dos escolares durante a dramatização e pelas falas dos escolares presentes na dramatização, captadas pela videogravação e pelas fitascassete, por meio do gravador. Os dados foram analisados por meio da análise temática com base no referencial teórico.

\section{Aplicações da dramatização em diferentes contextos da pesquisa}

A criança é capaz de demonstrar sentimentos, medos, percepções e preocupações pela intermediação do brincar. ${ }^{13}$ Assim, a escolha de estratégias metodológicas que se alicercem ou façam uso do brincar, por si só, já se mostram adequadas quando os sujeitos de pesquisa são crianças, posto que o brincar é uma linguagem que elas conhecem bem, o que favorece a comunicação.

A dramatização é uma estratégia de coleta de dados presente em várias pesquisas. Um estudo teve como objetivo conhecer o significado da hospitalização para crianças em idade pré-escolar. As autoras disponibilizavam brinquedos variados e bonecos representando a criança e sua família, e propunham aos pré-escolares que brincassem de criança internada, manipulando estes materiais à medida que faziam questionamentos pertinentes à temática do estudo. ${ }^{14}$

Em outra pesquisa, as autoras fizeram uso do brincar e da dramatização com brinquedos e materiais hospitalares para facilitar a orientação de uma criança de 3 anos sobre os procedimentos terapêuticos relacionados a uma intervenção cirúrgica. ${ }^{15}$ Em outra, foram usados brinquedos para fornecer explicações às crianças pré-escolares sobre a punção venosa. ${ }^{16}$

No presente estudo, a proposta da dramatização e seu uso na pesquisa foram explicados e prontamente entendidos pelas escolares. 
No início das dramatizações, ao chegarem ao cenário, basicamente todas as escolares tiveram muita curiosidade e interesse em manipular os objetos e brinquedos dispostos para uso nas representações. Algumas delas teciam considerações a respeito dos objetos, sobretudo quanto entravam em contato com eles durante procedimentos terapêuticos, como no caso de sondas nasogástricas.

Certamente, a liberdade de manipular materiais que são utilizados em procedimentos técnicos, que na maioria das vezes somente se tornam conhecidos mediante a experiência no procedimento, pode exercer grande fascínio na criança em idade escolar. Da mesma forma, essa experiência contempla uma necessidade da fase do desenvolvimento cognitivo do escolar, na qual a criança é bastante curiosa e deseja expandir seus conhecimentos sobre os objetos e situações encontradas em seu cotidiano. ${ }^{17}$

Em outro sentido, essa vivência serve para desmistificar esses objetos, que na maior parte das vezes, tem a conotação de dor e sofrimento para a criança, em especial, os que envolvem procedimentos de natureza invasiva.

No início da primeira dramatização de meu estudo, no momento da escolha dos papéis a serem representados pelas escolares, ocorreu um impasse, já que duas escolares queriam escolher papéis concomitantes. Todavia, essa questão foi solucionada, propondo-se um segundo momento de dramatização, no qual os papéis poderiam ser cambiados entre as escolares, o que acabou não acontecendo por decisão das próprias escolares.

Em relação à videogravação, as escolares não se sentiram incomodadas, exceto uma delas, que inicialmente se mostrou um pouco tímida diante da câmera. Mas quando expliquei que apenas eu veria as imagens, a criança não pareceu se preocupar mais e passou a agir com naturalidade diante da gravação.

Nesse aspecto, o pesquisador deve estar vigilante ao fazer uso da videogravação durante uma dramatização. Caso os sujeitos sintam-se pouco à vontade diante de câmera, ou mesmo tímidos, isso pode reprimi-los e influenciar na sua espontaneidade, vir a comprometer a veracidade da dramatização e produzir dados não tão ricos e fidedignos, em termos da representação dos papéis. A ambientação prévia do pesquisador junto aos sujeitos, com a finalidade de conhecê-los melhor e estabelecer uma relação de confiança, pode contribuir para minimizar essas ocorrências.

A dramatização possibilitou às escolares representarem os papéis de enfermeira, médica e paciente. Essas representações foram desenvolvidas com base no cotidiano da hospitalização, em que os cuidados vivenciados pelas escolares estiveram presentes.

Do mesmo modo, as escolares dramatizaram as atitudes, as intervenções e o cotidiano do médico e do enfermeiro, com base nas percepções advindas da vivência com esses profissionais.

Assim, a dramatização demonstrou ser uma estratégia metodológica que possibilita ao pesquisador conhecer as percepções, concepções e entendimento da criança em idade escolar sobre os diversos contextos da vida e papéis sociais, podendo se constituir em uma opção para estudos que venham a abordar esses aspectos.

\section{CONSIDERACCÕES FINAIS}

0 brincar e as brincadeiras não são apenas vias de prazer e entretenimento na infância. As crianças são capazes de lidar com ambiente, de elaborar acontecimentos e de se comunicar brincando.

A dramatização mostrou-se como uma estratégia viável e eficaz para coleta do material necessário à análise da pesquisa quando os sujeitos são crianças, em destaque, escolares. Além disso, se constituiu em uma experiência extremamente gratificante para as crianças. Para a criança, brincar é um ato muito fácil, é uma ação pertinente à infância. Sendo a dramatização também uma modalidade lúdica, foi possível às escolares vestirem-se dos papéis de enfermeira, médico e paciente e representá-los.

Essa foi uma atividade que fluiu naturalmente. A manipulação dos brinquedos que foram colocados à disposição das escolares na dramatização permitiu trazer para o âmbito da representação as cenas cotidianas vivenciadas pelas escolares no ambiente da unidade de pediatria.

As escolares incorporaram os papéis escolhidos na dramatização, brincaram, encenaram e vivenciaram esses papéis de uma forma livre, já que não havia script ou nenhuma espécie de direcionamento por parte da pesquisadora a ser seguido pelas escolares.

0 uso da filmadora e do gravador não se constituiu em um empecilho. Apenas uma escolar pareceu um pouco envergonhada no início da dramatização, ao perceber a filmadora. Todavia, esse comportamento exibido pela escolar logo desapareceu.

Desse modo, a dramatização foi uma abordagem que contemplou a viabilidade e a eficiência que devem estar presentes em um método que vise colher material para uma pesquisa, aliada à linguagem infantil do brincar. Por isso, vislumbro a dramatização como uma estratégia de coleta de dados promissora a ser usada por pesquisadores que desejem trabalhar com crianças em suas pesquisas qualitativas.

\section{REFERÊNCIAS}

1-Spindola AT, Santos RS. Trabalhando com a história de vida: percalços de uma pesquisa (dora?). Rev Esc Enferm USP 2003; 37(2): 11926.

2-Neves JL. Pesquisa qualitativa- características, usos e possibilidades. [on-line] Cad Pesq Administ 1996. 1(2). Disponível em: http:// www.ead.fea.usp.br/cad-pesq.

3-Marcus MT, Liehr PR. Abordagens de pesquisa qualitativa In: Wood GL, Haber J Pesq Enferm $4^{a}$ ed. Rio de Janeiro (RJ): Guanabara Koogan; 2001.

4-Polit DF, Hungler BP. Fundamentos da pesquisa em enfermagem. $3^{\mathrm{a}}$.ed. Porto Alegre (RS): Artes Médicas; 1995. 
A Dramatização no Espaço Hospitalar

Cibreiros Sa, Oliveira ICS

5-Minayo MCS. 0 desafio do conhecimento: pesquisa qualitativa em saúde. 6ª ed. São Paulo (SP): HUCITEC/ABRASCO; 1999.

6-Zanelli JC. Pesquisa qualitativa em estudos da gestão de pessoas. Est Psicol 2002; 7: 79-88.

7-Cibreiros SA. 0 cuidado sob a perspectiva do escolar hospitalizado: subsídios para enfermagem pediátrica [tese de doutorado]. Rio de Janeiro (RJ): Escola de Enfermagem Anna Nery/UFRJ; 2007.

8- Cibreiros SA. A comunicação do escolar por intermédio dos brinquedos: um enfoque para a assistência de enfermagem nas unidades de cirurgia pediátrica [dissertação de mestrado]. Rio de Janeiro (RJ): Escola de Enfermagem Anna Nery/UFRJ; 2000.

9- Vygostky LS. Psicologia pedagógica 2a.ed. São Paulo (SP): Martins Fontes; 2004

10- Resolução næ\%41, de outubro de 1995. Dispõe sobre os direitos da criança e do adolescente hospitalizadas. Diário Oficial da República do Brasil, Brasília (DF), 17 out 1995.

11- Pires D. Hegemonia médica na saúde e a enfermagem. São Paulo (SP): Cortez; 1989.
Esc Anna Nery Rev Enferm 2010 jan-mar; 14 (1): 165-70

12- Mello DF, Figueiredo GLA, Nascimento LC. A atualização da técnica de videogravação em investigação de enfermagem em saúde da criança. Rev Bras Enferm 2003 mar/abr; 56(2): 175-77.

13- Oliveira RO, Oliveira ICS. Os doutores da alegria na unidade de internação pediátrica: experiências da equipe de enfermagem. Esc Anna Nery Rev Enferm 2008 jun; 12(2): 230-36.

14- Ribeiro CA, Ângelo M. 0 significado da hospitalização para a criança pré-escolar: um modelo teórico. Rev Esc Enferm USP 2005; 39(4): 391-400.

15- Faleiros F, Sadala MLA, Rocha EM. Relacionamento terapêutico com criança no período perioperatório: utilização do brinquedo e da dramatização. Rev Esc Enferm USP 2002; 36(1): 58-65.

16- Martins MR, Ribeiro CA, Borba RIH, Silva CV. Protocolo de preparo da criança pré-escolar para punção venosa, com utilização do brinquedo terapêutico. Rev Latino-am Enfermagem 2001 mar; 9(2): 76-85.

17- Wong D.L. Enfermagem Pediátrica. elementos essenciais à intervenção efetiva. $5^{\text {a }}$ ed. Rio de Janeiro (RJ): Guanabara Koogan; 1999.

\section{NOTAS}

${ }^{\text {a }}$ A dramatização como método de coleta de coleta de dados foi utilizada na tese de doutorado intitulada: 0 cuidado sob a perspectiva do escolar hospitalizado: subsídios para enfermagem pediátrica.(Cibreiros,2007) ${ }^{7}$

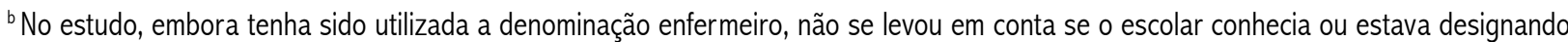
enfermeiro como o profissional de nível superior. A denominação enfermeiro correspondeu a qualquer membro da equipe de enfermagem que presta cuidado à criança. 